\title{
Monitoring of the Impacts of Used Materials for Resulting Attributes of an Electric Motor Created via Additive Technology
}

\author{
Jozef Török, Martin Pollák, Monika Töröková, Zuzana Murčinková, Marek Kočiško
}

Technical University of Kosice, Faculty of technologies with a seat in Presov, Bayerova 1, 08001 Prešov, Slovakia

\begin{abstract}
The article discusses the possibilities of production of a brushless electric motor with usage of additive technologies and verification the functionality of the design. A few electromotor stators have been produced by 3D printing. They were made of PLA plastic with different admixtures to increase the intensity of the magnetic field. The contribution at the end offers a comparison comprising the individual measurements and the efficiency of the electric motor.
\end{abstract}

Keywords - additive technology, electromotor, AC electric motor, PLA plastic

\section{Introduction}

The electric motor is the easiest way to convert electricity to useful mechanical energy. This device has played an important role in increasing the productivity of modern industry, and is therefore one of the reasons for the higher standard of life. Nowadays, it is an indispensable part of most industrial production around the world. The basic principles of electromagnetic induction were discovered in the early 19th century by several inventors.

DOI: $10.18421 /$ TEM92-54

https://doi.org/10.18421/TEM92-54

Corresponding author: Jozef Török,

Technical University of Kosice, Faculty of Manufacturing technologies with a seat in Presov, Prešov, Slovakia.

Email: jozef.torok@tuke.sk

Received: 18 April 2020.

Revised: 15 May 2020.

Accepted: 22 May 2020.

Published: 27 May 2020.

(c) BY-NC-ND (C) 2020 Jozef Török at al; published by UIKTEN. This work is licensed under the Creative Commons Attribution-NonCommercial-NoDerivs 4.0 License.

The article is published with Open Access at www.temjournal.com
In 1820, Hans Christian Oersted discovered the dependence between electricity and magnetism by being able to deflect a magnetic needle by means of an electric shock. Later, he discovered the deflection of the magnet by the electric current. [1] The magnet that is placed on the wire is rotated by the electrical current. This deflection is greater if there is a higher electric current. Deviation size also depends on the magnet distance from the driver. For his discoveries, the magnetic field strength unit was named CGS Oersted (Oe). Michael Faraday, with a series of attempts in 1821, discovered the electromagnetic rotation, which is the basic principle of an electric motor. In 1831 he discovered electromagnetic induction. He proved that electricity and magnetism are two different manifestations of one phenomenon - electromagnetism. [4]

Since then, the development of electric motors has gone a long way and its variations have become an indispensable everyday part of all kinds of equipment. Additive technologies let us away from used production methods, where complex functional units are made from simpler components. We still do not have the capacity to produce a functional actuator with one production process, but the first steps have been taken. [3]

\section{Basic Principles}

Most electric motors are rotating around their axis, but there are also special motors that move linearly. All electric motors work on DC or AC current, or work with both. Depending on the end use, each engine has its unique characteristics. The body consists of two basic parts, namely the rotor and the stator. The title of these parts implies that the rotor is a part of the electric motor that rotates about the axis and the stator is a fixed, immobile part. The design and manufacture of these two parts determines the engine's classification and characteristics. Other components such as brushes, sliding rings, fans, bearings, and capacitors can be unique to each type of engine. In an electric motor, the magnitude of the 
force varies directly with the intensity of the magnetic field and the amount of current flowing through the conductor. Electric motors work on the principle of electromagnetism. Due to the magnetic field generated in the vicinity of the coil winding, when the current passes through it, and the action of the permanent magnet which evokes rotation. [2]

The electrical current from the power supply is coupled in the motor conductor terminals. These terminals lead the electrical current to rotor if it contains a coil winding with a pair of loose connectors. The connectors, or as they are slangcalled brushes which can be made of graphite, thin metal strips or metal wires can be pressed on a commutator with simple springs. [7] presented embodiment, which is a sample of brushless motor. The winding of the coil together with the plastic core forms the stator of an electric motor as in Figure 1.

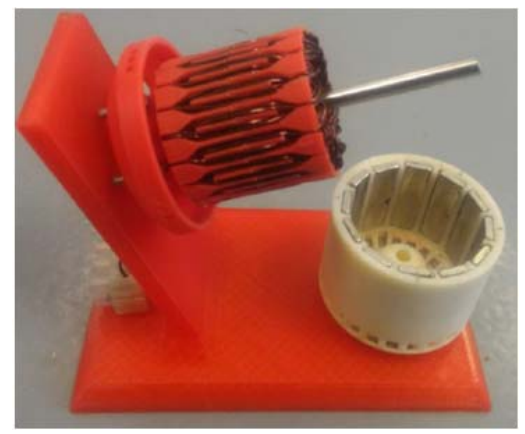

Figure 1. Stator and rotor of 3D-printed electric motor

The rotor is made of an outer casing in which permanent magnets are placed, which usually form two to several dozen pole pairs with alternate northern and southern poles. The layout of these magnets is different, but it always has to be an even number, in our case its 12. In Figure 2 we can see an example of simplified storage of three pairs of permanent magnets.

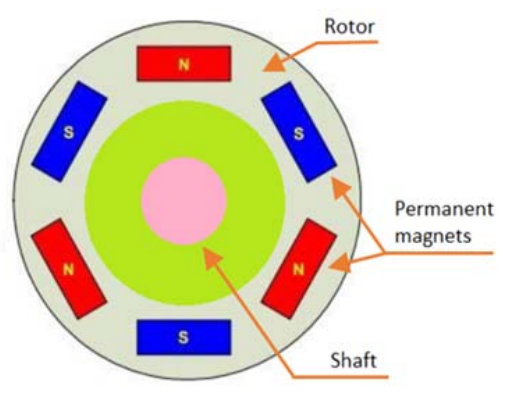

Figure 2. Magnet storage in the rotor

Based on the desired magnetic field density, a suitable magnetic material is selected for the assembly in the rotor. Traditionally, ferrite magnets are used for rotors. With advances in technology, new materials come from rare minerals. Ferrite magnets are much cheaper, but their disadvantage is in their low magnetic flux density compared to alloys of the same size. These alloy magnets have a high magnetic flux density and therefore allow the rotors to shrink in size while maintaining the torque. Basic parameters in the Table 1.

Table 1. Magnetic materials properties

\begin{tabular}{|c|c|c|c|c|}
\hline TYPE & $\begin{array}{c}\text { COMPOSI } \\
\text { TION }\end{array}$ & ๑ & 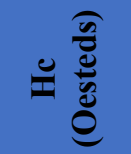 & 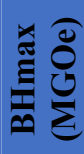 \\
\hline Neodymium & $\begin{array}{l}\text { Neodymium } \\
\text {, iron and } \\
\text { boron }\end{array}$ & 13,000 & 11,5000 & 42 \\
\hline Alnico & $\begin{array}{l}\text { Aluminium, } \\
\text { nickel, } \\
\text { cobalt, iron }\end{array}$ & 12,500 & 640 & 5,5 \\
\hline Ferrite & $\begin{array}{l}\text { Ceramic } \\
\text { materials } \\
\text { and iron } \\
\text { oxide }\end{array}$ & 3,850 & 2,950 & 3,5 \\
\hline $\begin{array}{c}\text { Samarium } \\
\text { cobalt }\end{array}$ & $\begin{array}{l}\text { Samarium } \\
\text { and cobalt }\end{array}$ & 11,000 & 9,700 & 28 \\
\hline
\end{tabular}

$\mathrm{Br}-$ Volume of magnetism

$\mathrm{Hc}$ - Resistance to demagnetisation

BHmax - Maximum energy product

\subsection{DC electric motor}

In modern DC motors, as with modern generators, the current acts on the stationary part of the engine, and the magnets are on the rotor. It can be the opposite by using a commutator. The alternating current in the stator creates a rotating magnetic field that acts on the magnetic field of the rotor and thereby forces it to rotate. Motors have several options for generating the magnetic field of the rotor. In some rotors, permanent magnets are stored, in other rotors, they consist of electromagnets powered by an external DC source, and in induction motors the rotor captures induced magnetic fields from the magnetic field of the stator. [6]

\section{Building the Motor}

The body of the engine was made according to the freely expandable Brushless Motor v2 on the makeSEA 3D print technology. [5] We can use multiple methods to increase the rotational force or torque. One of these solutions is to install stronger magnets (in our case, neodymium magnets were used), we can increase the electric current flowing through the spool, or we can increase the number of loops in the spool by using a thinner wire instead of one loop of larger diameter wire. Increasing engine power is also possible by reducing the distance between the coil and the magnet. The smaller distance between coil and magnet is, the stronger are magnetic forces they generate. For the purpose of 
comparing the parameters of the 3D-produced engine with PLA plastic, the same coiling of coil was used once on the core of pure PLA plastic and then on the cores containing metallic additives in the PLA plastic as seen on Figure 3.

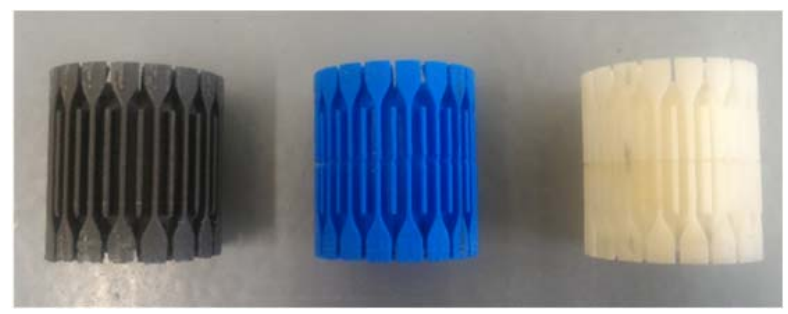

Figure 3. Named from the left, cores created from materials: Composite PLA, PLA, ABS

Used Composite PLA material - Rustable Magnetic Iron comes from the American company Proto-Pasta. It responds to the magnets and behaves similarly to pure iron. Weighted feel with $1.5 x$ the density of standard PLA and induction at magnetic saturation is about 0.15 Tesla. Relative (to air) Permeability is between 5 and 8 independent of frequency up to 1 $\mathrm{MHz}$.

Experiments with this material have clearly shown that the magnetic PLA is much less magnetic than ordinary steel materials due to lower metal density in the plastics. The advantage of this material is that it is not conductive, and therefore there is no danger that a coil will occur when winding coils. Due to the formation of the vortex streams, the normal core is composed of metallic slices. When using a composite of PLA and iron, the explosive currents do not arise because the individual grains of the dust are completely isolated.

The stator core was produced and based on the STL data accessible under the name: BL_StatorWindingCoreA and BL_StatorWindingCoreB. Due to the spatial printer parameter, we were able to produce the core in one piece by linking the STL files without the need for subsequent gluing. The printer used for the production of individual parts was: ZMorph 2.0SX with a single 1.75 toolhead and $0.4 \mathrm{~mm}$ nozzle.

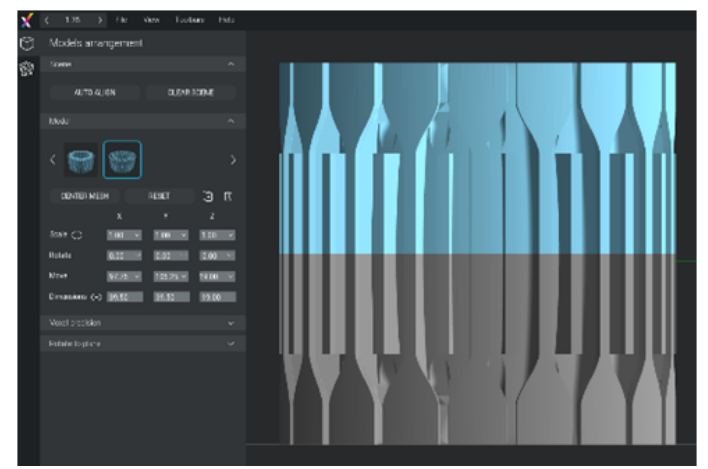

Figure 4. Voxelizer 2 enviroment
The printing time was 3 hours 7 minutes. The same conditions were used in the manufacture of a core of conventional PLA plastic, but the printing temperature was decreased from $230{ }^{\circ} \mathrm{C}$ (for Composite PLA) to only $200{ }^{\circ} \mathrm{C}$. Other printed components were the stator core, cover and the rotor body. In addition, commonly available components were used:

- $\quad$ Shaft - diameter $5 \mathrm{~mm}$, length $90 \mathrm{~mm}$

- 2 bearings - inner diameter $5 \mathrm{~mm}$, outer diameter $9 \mathrm{~mm}$, width $4 \mathrm{~mm}$,

- $4 \mathrm{x}$ nuts and bolts - M3, nuts $2.5 \mathrm{~mm}$ thick, 5.5 $\mathrm{mm}$ smaller diameter,

- 12 neodymium magnets - $30 \mathrm{~mm}$ long, $10 \mathrm{~mm}$ wide, $2.8 \mathrm{~mm}$ thick,

- $7.5 \mathrm{~m}$ copper wire - enamelled, diameter $1 \mathrm{~mm}$.

\subsection{Winding}

The stator core has 36 slots; the end of each slot has a special shape that helps guide the wire and hold it firmly inside the slot. For this reason, winding is easier to assemble, and no further reeling tools are required. If the wire has a larger diameter, it has lower flexibility and more force needs to be used. Expanded slot ends do not play any special role in engine performance, and they work only as a cover. The basic scheme is very simple. The engine has three coils or otherwise called phases (A - red, B green, $\mathrm{C}$ - blue). In each slot, the current has to flow in the same direction in all wires. If the current would flow in the opposite direction in a wire, the magnetic effect would be neutralized. The core was wound up gradually, this means that phase A was wound first, then phase B and finally phase C. The winding of the last phase was the longest since the wire had to be stretched between the winding phases $\mathrm{A}$ and $\mathrm{B}$. The winding ends on one side are then connected to create a star connection as seen on Figure5.

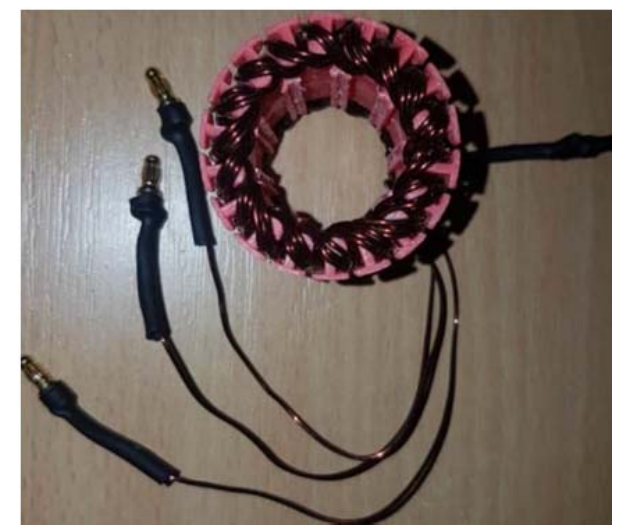

Figure 5. Winding on the stator core with connectors

In the subsequent step, the bearings and the nuts for the grip of the engine were mounted in the stator 
guard. For easier and more precise placement of bearings, the holes should be precisely machined to prevent the shaft from being misaligned. Wrong placement of the rotor or the stator rotor creates friction which can result in overheating and power loss.

\section{Measurement}

During the measurement, motor was connected to a stable DC voltage source and the engine speed was controlled by the ECS controller and servo tester. The ESC controller FlyFun 40A and G.T. servo tester was connected to alternating motor on a singlesource power supply. This measurement was a proof of concept and therefore only the values of voltage, current, coil resistance and no load were measured.

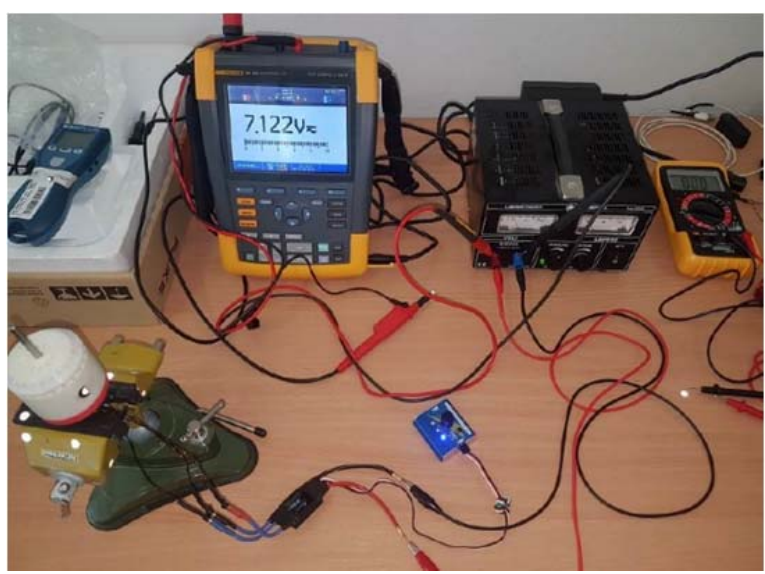

Figure 6. Basic measurement setup

The following measuring instruments were used for these measurements:

- Fluke 190-202 ScopeMeter - Used to measure resistance and voltage.

- Fluke 289 True-rms Multimeter - Used to measure current.

- Monarch Pocket Laser Tach 200 - Used for speed measurement.

The measurement was based on the results of the primary prototype diagnostics with a copper wire of $1 \mathrm{~mm}$ in diameter. Selected sample values can be seen in Table 2.

Table 2. Parameters for MakeSea motor with parts made of PLA

\begin{tabular}{|c|c|c|}
\hline $\begin{array}{c}\text { Current } \\
{[\mathbf{A}]}\end{array}$ & $\begin{array}{c}\text { Voltage } \\
\text { [V] }\end{array}$ & $\begin{array}{c}\text { Motor Speed } \\
\text { [RPM] }\end{array}$ \\
\hline $\mathbf{0 , 5 5}$ & 7,65 & 1500 \\
\hline $\mathbf{0 , 7}$ & 7,65 & 2120 \\
\hline $\mathbf{1 , 0 4}$ & 7,64 & 2450 \\
\hline $\mathbf{1 , 5}$ & 7,6 & 2970 \\
\hline $\mathbf{2 , 0 8}$ & 7,58 & 3400 \\
\hline $\mathbf{2 , 5 0}$ & 7,6 & 3640 \\
\hline
\end{tabular}

As seen in Table 3, the values are measured in our laboratory on motor where the stator core was made of conventional PLA largely exceeded the prototype results.

Table 3. Stator from PLA

\begin{tabular}{|c|c|c|}
\hline $\begin{array}{c}\text { Current } \\
{[\mathbf{A}]}\end{array}$ & $\begin{array}{c}\text { Voltage } \\
\text { [V] }\end{array}$ & $\begin{array}{c}\text { Motor Speed } \\
{[\text { RPM] }}\end{array}$ \\
\hline $\mathbf{0 . 8}$ & 7,65 & 2057 \\
\hline $\mathbf{1 . 1}$ & 7,65 & 3080 \\
\hline $\mathbf{1 . 1 8}$ & 7,65 & 3814 \\
\hline $\mathbf{1 , 2 3}$ & 7,65 & 4522 \\
\hline $\mathbf{1 , 3 4}$ & 7,65 & 5193 \\
\hline $\mathbf{1 , 5}$ & 7,65 & 6887 \\
\hline
\end{tabular}

Higher measured rotation speeds could be achieved by better engine winding and more precise storing of individual components. The following measurement, as seen in Table 4, contains values from measurement of the core made of composite PLA, printed in one piece. More stable measurement conditions have been achieved thanks to the use of a hard power source to ensure constant voltage throughout the measurement.

Table 4. Parameters for motor with parts made of composite PLA

\begin{tabular}{|c|c|c|}
\hline $\begin{array}{c}\text { Current } \\
{[\mathbf{A}]}\end{array}$ & $\begin{array}{c}\text { Voltage } \\
{[\mathbf{V}]}\end{array}$ & $\begin{array}{c}\text { Motor Speed } \\
{[\text { RPM] }}\end{array}$ \\
\hline 0.815 & 7,65 & 2110 \\
\hline $\mathbf{1 . 0 9}$ & 7,65 & 3263 \\
\hline $\mathbf{1 . 1 8}$ & 7,65 & 3931 \\
\hline $\mathbf{1 . 3 1}$ & 7,65 & 5341 \\
\hline $\mathbf{1 . 5 7}$ & 7,65 & 5970 \\
\hline $\mathbf{1 . 6 0}$ & 7,65 & 7089 \\
\hline
\end{tabular}

Measurements on Figure 6 show that, regardless of the material used and the quality of the production process at lower currents, approximately the same speed is achieved but the torque increases with the quality of the assembly.

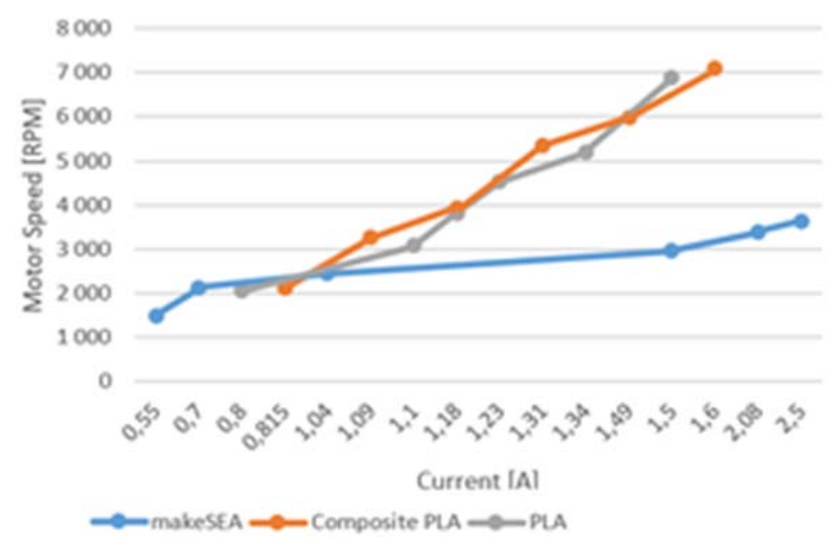

Figure 7. Motor speed based on current flow 


\section{Conclusions}

The article proved that it is possible to produce components of sufficient parameters for the production of an electric motor by applying additive technology. However, further research is needed to improve the properties of the used materials. With higher operating speeds, PLA plastic is heated, which can result in instability of the entire structure. Likewise, PLA is relatively quickly subject to external influences, which has a large impact on the meanings of reproduction for other users and researchers. To increase the effect of electromagnetic effects, it is necessary to increase the proportion of metallic additions in the used composite. Steps have to be taken to ensure stable reproduction of the results. It is advisable to continue and address the issue of producing functional assemblies using 3D printing techniques, with the aim of producing them in one process step. Although these products are not yet equaled by a commercially produced product, but in some cases they can be a temporary solution to many problems.

\section{Acknowledgements}

This article was supported by the Agency to support research and development under contract number $A P V V$ 18-0316 and VEGA 1/0026/19.

\section{References}

[1]. Dobránsky, J., Baron, P., Vojnová, E., \& Mandul'ák, D. (2016). Optimization of the production and logistics processes based on computer simulation tools. In Key engineering materials (Vol. 669, pp. 532-540). Trans Tech Publications Ltd.

[2]. Karthikeyan, J. (2014). Investigations on current control and speed control of VSI CSI fed permanent magnet brushless dc motor.

[3]. Panda, A., Prislupčák, M., \& Pandová, I. (2014). Progressive technology diagnostics and factors affecting machinability. In Applied Mechanics and Materials (Vol. 616, pp. 183-190). Trans Tech Publications Ltd.

[4]. Mohamed, O. A., Masood, S. H., \& Bhowmik, J. L. (2017). Experimental investigation of time-dependent mechanical properties of PC-ABS prototypes processed by FDM additive manufacturing process. Materials letters, 193, 58-62.

[5]. Afrose, M. F., Masood, S. H., Iovenitti, P., Nikzad, M., \& Sbarski, I. (2016). Effects of part build orientations on fatigue behaviour of FDM-processed PLA material. Progress in Additive Manufacturing, 1(1-2), 21-28.

[6]. Novakova-Marcincinova, L., \& Kuric, I. (2012). Basic and advanced materials for fused deposition modeling rapid prototyping technology. Manuf. and Ind. Eng, 11(1), 24-27.

[7]. Novak-Marcincin, J., Barna, J., Janak, M., \& Novakova-Marcincinova, L. (2013). Augmented reality aided manufacturing. Procedia Computer Science, 25, 23-31. 